\title{
Dysharmonic Maturation of the Hand in the Congenital Malformation Syndromes
}

\author{
ANDREW K. POZNANSKI, STANLEY M. GARN, \\ LAWRENCE R. KUHNS AND \\ SAM T. SANDUSKY \\ Department of Radiology and the Center for Human Growth and \\ Development, The University of Michigan, \\ Ann Arbor, Michigan 48104
}

\begin{abstract}
In many congenital malformation syndromes the pattern of hand-wrist development does not fit the sequence pictured in the Greulich-Pyle atlas. Not infrequently, there is a difference in maturation level of carpal and phalangeal centers in excess of that found in clinically normal children. Usually, the carpal centers are less developed than the phalangeal centers, whereas overall skeletal maturation is retarded (as in trisomy 18) or advanced (as in cerebral gigantism). In still other conditions, specific carpal centers are disproportionately delayed. By way of example, the capitate is differentially delayed in epiphyseal dysplasia, the lunate in homocystinuria, and the scaphoid in Fanconi's anemia and other radial hypoplasia syndromes. Side to side (i.e., bilateral) asymmetries may also occur in the developing hand, as in paralysis, in conditions involving increased local vascularity (as in hemangioma and rheumatoid arthritis) or in conditions associated with decreased vascularity.

In the presence of excessive dysharmonic development or major bilateral asymmetry, with or without agenesis of one or more hand bones, assigning meaningful bone ages in congenital malformation syndromes becomes difficult. On the other hand, the degree and pattern of dysharmonic maturation may be helpful in diagnosis.
\end{abstract}

There is frequently difficulty in evaluating skeletal maturation of children when the pattern does not fit the classic patterns described in the literature. This problem is compounded in children affected with the congenital malformation syndromes because of the high incidence of unusual ossification sequences or patterns and abnormality of configuration of epiphyses and carpals. When variation from normal is extreme, the concept of skeletal age becomes less meaningful (fig. 1).

In our search for a name for these local variations in maturation, Alex Roche of the Fels Research Institute suggested the term - "dysharmonic maturation." The analysis of these abnormalities in the congenital malformations will be the subject of this paper.

We will consider dysharmonic maturation, either from the point of view of onset of ossification (Garn, Rohmann and Silverman, '67), or on the basis of maturity indicators (Greulich and Pyle, '59). It certainly would be possible to consider it also on the basis of completion of ossification (Stuart et al., '62).

In considering dysharmonic maturation of the hand, we will include (1) differences in ossification rate between the carpals and the phalangeal epiphyses, (2) delay or advancement of specific centers, and (3) side to side asymmetry. We will not consider differences in maturation between various portions of the body. Certainly these occur in both normal and abnormal individuals (Garn, Rohmann and Silverman, '67), but so far we have relatively little data on this type of dysharmony in the malformation syndromes. We have seen differences in maturation of the teeth and knees in infants with several congenital anomalies, but the data is still sketchy and evaluation tenuous.

There is considerable variation in ossification order even in a normal population. In considering only six of the carpals, Garn and Rohmann ('60a) found that only $49 \%$ of boys and $61 \%$ of girls 


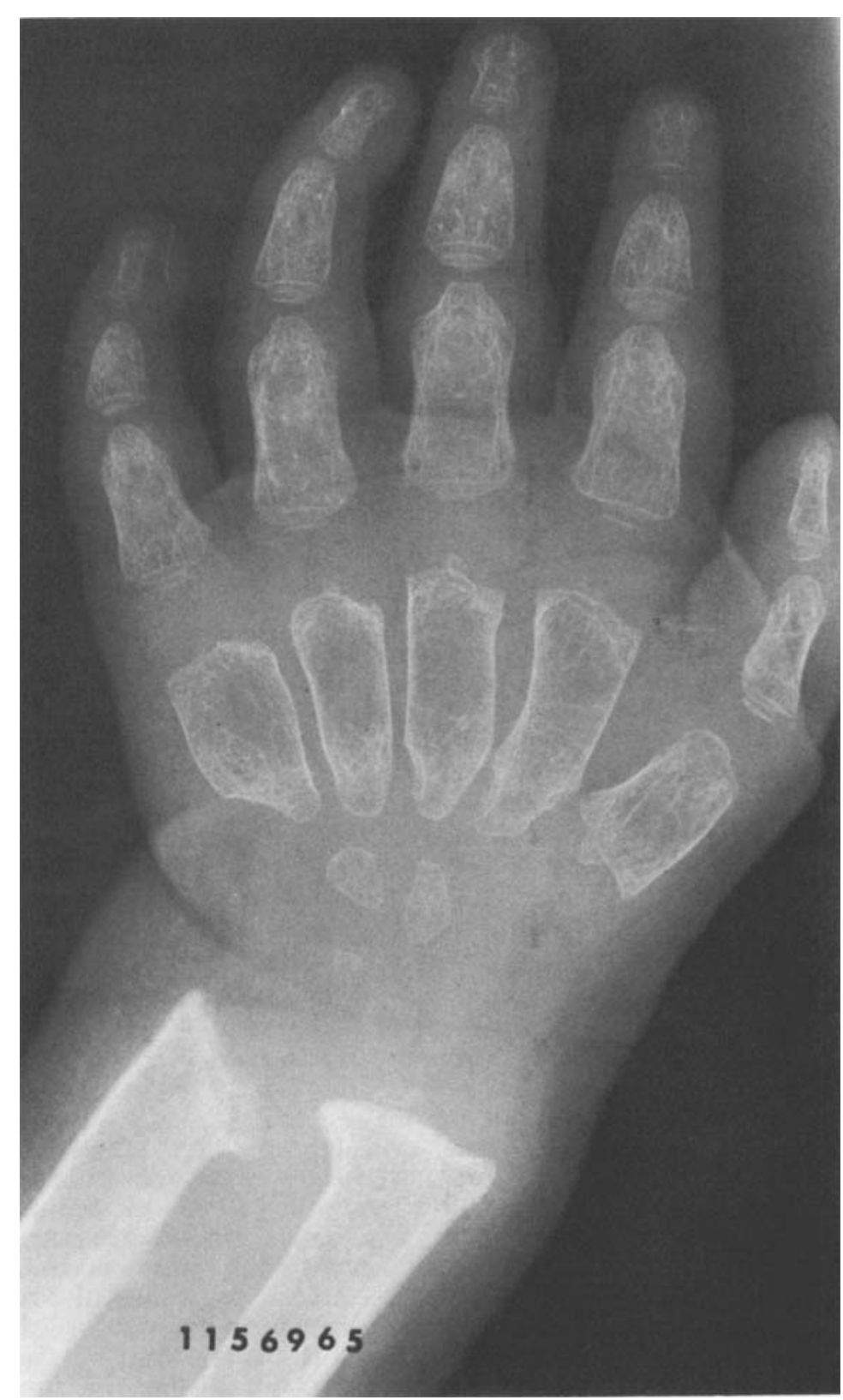

Fig. 1 Hurler's syndrome. Five and eight-tenths year old female. There is marked retardation of the capitate and hamate with irregularity of their margins. The epiphyses are also irregular and retarded. When marked abnormality of configuration is present, evaluation of skeletal age becomes less meaningful.

followed the capitate-hamate-triquetrumlunate-trapezium-trapezoid order. For these six bones alone, 13 different sequences were observed in normal boys and ten in normal girls. Differences are also evident when various normal series are compared (Stuart et al., '62; Garn and Rohmann, '60a). Variations in sequence also exist between males and females (Garn, Rohmann and Blumenthal, 
'66). The triquetrum, for example, according to Stuart et al. ('62), is the sixteenth bone in the male and twenty-third bone in the female. In the data of Garn and Rohmann ('60a) the difference is not as extreme. Sequence variation is also related to race (Lee et al., '68) and may also be genetically determined. Garn, Rohmann and Davis ('63) found a correlation between children and their parents (about 0.3). There was higher correlation between siblings ( 0.4 to 0.6 ) and even higher correlations between monozygotic twins (about 0.9). Generally speaking, sisters are more alike in ossification timing than brothers. Malnutrition has been associated with an increased frequency of abnormal sequences (Dreizen et al., '64). This may, however, be due to their slow maturation rate. Garn, Rohmann and Blumenthal (66) have shown that a slow rate of ossification tends to produce an apparently large number of abnormal sequences if a longitudinal study is not used, since the sampling procedure tends to separate out sequences so they are seen rather than being missed.

Also, when children below the fifth percentile of number of centers, using the standard of Garn and Rohmann ('60b), were compared to those above the ninetyfifth percentile of centers in the ten state
Nutrition Survey different onset ossification sequences were evident (table 1). The term "relative delay of a carpal" is used for the situation when a carpal is absent but at least one center which "normally" follows it is present. Relative advancement of a carpal means that a carpal was present ahead of some phalangeal or metacarpal epiphysis which "normally" is present before it. The "normal" sequence with which these ossification patterns were compared was the median sequence described by Garn, Rohmann and Silverman ('67). The triquetrum was relatively delayed in $28.5 \%$ of the retarded (5th percentile group of the 10 state $\mathrm{Nu}$ trition Survey), but in only $11.5 \%$ of the advanced group (95th percentile). Some carpal bone was relatively advanced in $18.7 \%$ of the advanced group, but only in $3.3 \%$ of the retarded group. The most commonly advanced bone in the ninetyfifth percentile group was the lunate. From these data it is evident that in the evaluation of sequence variation in children with markedly delayed or advanced maturation in the malformation syndromes a group of normal children with similarly advanced or retarded maturation should be used as controls.

There may be a lack of parallelism between the sequence of onset of ossifica-

TABLE 1

Incidence of sequence variations in advanced and retarded males

\begin{tabular}{|c|c|c|c|c|c|}
\hline & \multicolumn{2}{|c|}{$\begin{array}{l}\text { Fifth percentile } \\
\text { (retarded) }\end{array}$} & \multicolumn{2}{|c|}{$\begin{array}{l}\text { Ninety-fifth percentile } \\
\text { (advanced) }\end{array}$} & \multirow[b]{2}{*}{$x^{2}$} \\
\hline & $\mathrm{N}$ & $\begin{array}{l}\text { Per cent of total } \\
\text { in fifth } \\
\text { percentile }\end{array}$ & $\mathbf{N}$ & $\begin{array}{l}\text { Per cent of total } \\
\text { in ninety-fitth } \\
\text { percentile }\end{array}$ & \\
\hline Total males & 151 & & 96 & & \\
\hline Toatal "abnormal" 1 sequence & & 59.0 & 47 & 49.0 & 1.06 \\
\hline \multicolumn{6}{|l|}{$\begin{array}{l}\text { Some relative delay of } \\
\text { onset of }\end{array}$} \\
\hline Triquetrum & 43 & 28.5 & 11 & 11.5 & 7.79 \\
\hline Lunate & 4 & 2.6 & 2 & 2.1 & 0.03 \\
\hline Scaphoid & 13 & 8.6 & 8 & 8.3 & 0.02 \\
\hline Trapezium & 18 & 11.9 & 6 & 6.2 & 1.38 \\
\hline Trapezoid & 5 & 3.3 & 1 & 1.0 & 0.45 \\
\hline \multicolumn{6}{|l|}{$\begin{array}{l}\text { Some carpal relatively } \\
\text { advanced to a phalangeal }\end{array}$} \\
\hline or metacarpal epiphysis & 5 & 3.3 & 18 & 18.7 & 13.56 \\
\hline \multicolumn{6}{|l|}{ Triquetrum relatively } \\
\hline advanced & 2 & 1.3 & 6 & 6.2 & 3.03 \\
\hline Lunate relatively advanced & 3 & 2.0 & 12 & 12.5 & 9.13 \\
\hline
\end{tabular}

This is based on children in the ten state Nutritional Survey.

Sequence used as "normal" was that described by Garn, Rohmann and Silverman ('67). 
tion and relative maturation of each center using the maturational indicators of Greulich and Pyle.

To consider an ossification pattern abnormal in the congenital malformation, it has to be present in a significantly large number of cases and be significantly different from normal sequences in a similar population. A very real prob- lem is that in many of these disorders the number of cases seen by any observer is small.

$$
\begin{aligned}
& \text { CONDITIONS WITH DIFFERENCES IN } \\
& \text { CARPAL AND PHALANGEAL OR } \\
& \text { METACARPAL MATURATION }
\end{aligned}
$$

In many congenital malformation syndromes the carpals are relatively delayed in comparison to the phalangeal epiphy-

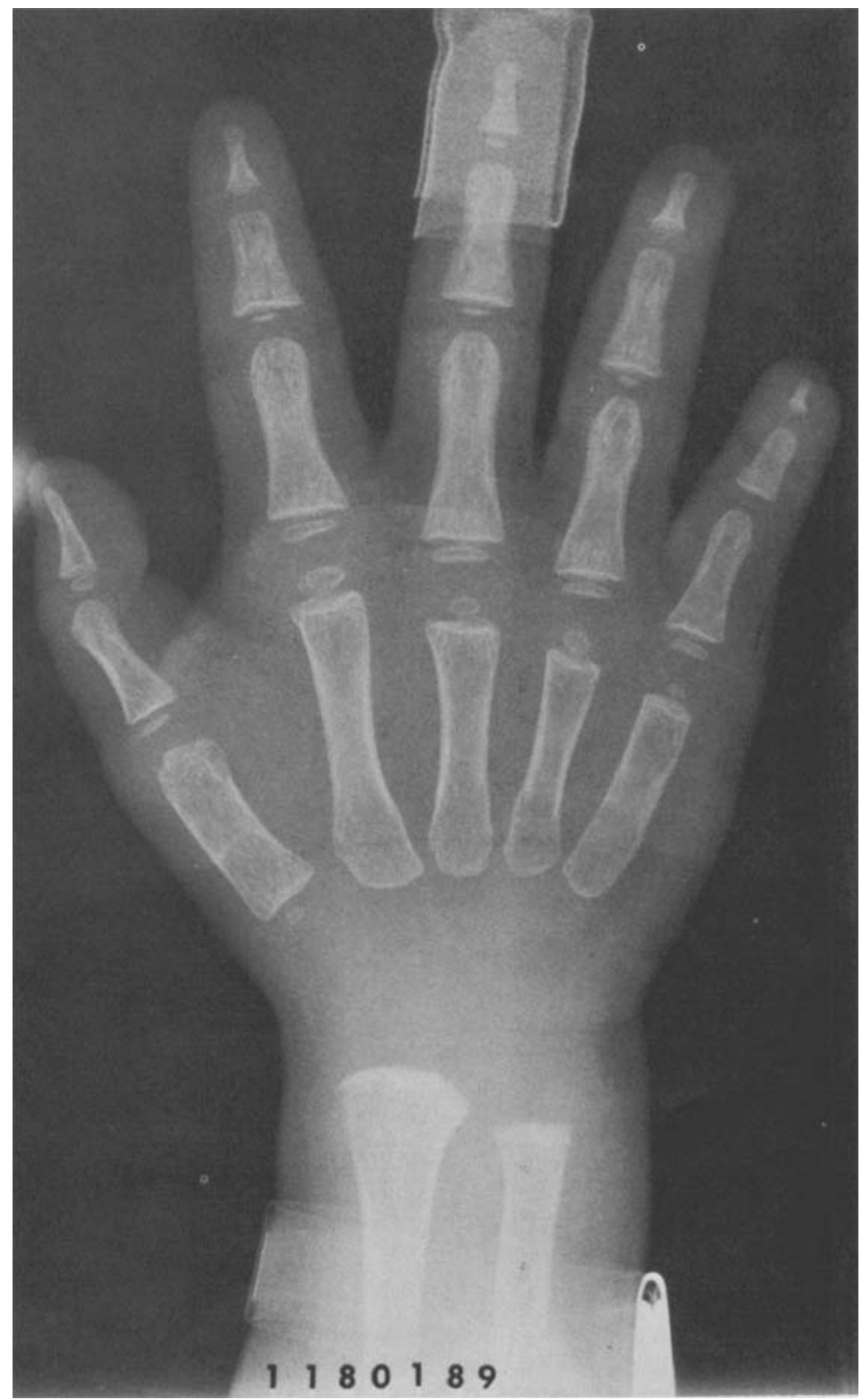

Fig. 2 Trisomy 18. Forty-two month old female showing differential carpal delay. No carpal ossification centers are apparent, while most of the epiphyses are present. 
ses, whether associated with retarded maturation, as in trisomy 18 , or advanced maturation as in cerebral gigantism.

Trisomy 18 is a chromosomal disorder which is usually fatal in the first year of life. In four cases from different sources, which were mature enough to have some phalangeal and metacarpal epiphyses, the retardation of the carpals was much greater than the phalanges, although both were retarded (table 2). The differences

TABLE 2

Difference between carpal and phalangeal maturation in trisomy 18 children

\begin{tabular}{lllll}
\hline & 1 & $2^{1}$ & $3^{2}$ & 43 \\
\hline $\begin{array}{l}\text { Sex } \\
\text { Chronologic age }\end{array}$ & $F$ & $F$ & $F$ & $F$ \\
$\begin{array}{l}\text { Months } \\
\text { Phalangeal age }\end{array}$ & 42 & 30 & $\approx 36$ & 120 \\
$\begin{array}{c}\text { Months } \\
\text { Carpal age } \\
\quad \text { Months }\end{array}$ & 24 & 24 & 17 & 69 \\
$\begin{array}{c}\text { Difference between } \\
\text { phalangeal and } \\
\text { carpal age }\end{array}$ & $<3$ & $<3$ & $<3$ & 28 \\
$\quad$ Months & $>21$ & $>21$ & $>14$ & 41 \\
\hline
\end{tabular}

${ }^{1}$ Follow-up films, Courtesy Dr. John Gall, Plymouth State Home and Training School, Northville, Michigan

2 Films supplied courtesy of Dr. L. Weiss and Dr.

John Kirkpatrick, St. Christopher's Hospital, Philadelphia.

3 Evaluation of films published in Ozonoff et al. 1964. American J. Roentgenol., 91: 626.

Bone ages were determined using the Pyle and Greulich standards and are average for two observers (AKP, LRK). varied from 14 to 41 months. In some cases phalangeal epiphyses are present but the carpals are absent (fig. 2). This sequence is not present in normal populations (Garn and Rohmann, '60a). Not a single example of phalangeal centers occurring ahead of capitate or hamate was found in about 6800 children in the ten state Nutrition Survey.

Cerebral gigantism (Poznanski and Stephenson, '67) is a condition of accelerated growth with advanced skeletal maturation in which the "bone age" is equal to the "height age." These children are mentally retarded and have characteristic faces with high forehead and prominent mandible. The hands and feet are large. The condition is probably due to a hypothalamic atrophic lesion and is more common in males.

Maturation of the various hand ossification centers was evaluated in nine male cerebral giants, using the Greulich and Pyle standards. Some of the patients had radiographs at several ages. An average of the maturation of the phalanges and metacarpals was compared to the average of the carpal centers (table 3 ). Although both were usually advanced, in almost all cases there was a significantly greater phalangeal-metacarpal age than carpal age (fig. 3). This difference was as high as 2.8 years. It was less consistent during infancy than in later childhood,

TABLE 3

Relative advancement of epiphyses of the digits in cerebral giants

\begin{tabular}{lccccc}
\hline & $\begin{array}{c}\text { Chronological } \\
\text { age }\end{array}$ & $\begin{array}{c}\text { Average phalangeal } \\
\text { and metacarpal age }\end{array}$ & $\begin{array}{c}\text { Average carpal } \\
\text { age }\end{array}$ & $\begin{array}{c}\text { Difference between } \\
\text { epiphyseal age and } \\
\text { carpal age }\end{array}$ \\
\hline & & years & years & years & years \\
RH & M & 0.8 & 1.5 & 0.8 & 0.7 \\
& & 1.2 & 1.8 & 1.8 & 0.0 \\
DJ & M & 2.3 & 3.2 & 1.4 & +1.8 \\
& & 3.2 & 4.3 & 1.9 & +2.4 \\
TF & M & 2.7 & 4.2 & 2.0 & +2.2 \\
MB & M & 3.5 & 4.7 & 4.7 & 0 \\
RD & M & 0.7 & 1.8 & 1.6 & +0.2 \\
& & 1.3 & 2.6 & 2.3 & +0.3 \\
KB & M & 4.2 & 5.6 & 5.1 & +0.5 \\
& & 0.8 & 1.4 & 2.8 & -1.4 \\
RG & M & 4.3 & 9.2 & 7.4 & +1.8 \\
& & 6.3 & 8.9 & 6.1 & +2.8 \\
DM & F & 2.6 & 4.4 & 2.8 & +1.6 \\
& & 5.9 & 8.8 & 8.3 & +0.5 \\
MS & M & 7.7 & 10.2 & 10.3 & +1.6 \\
& & 9.8 & 1.4 & 5.8 & +0.7 \\
\hline
\end{tabular}




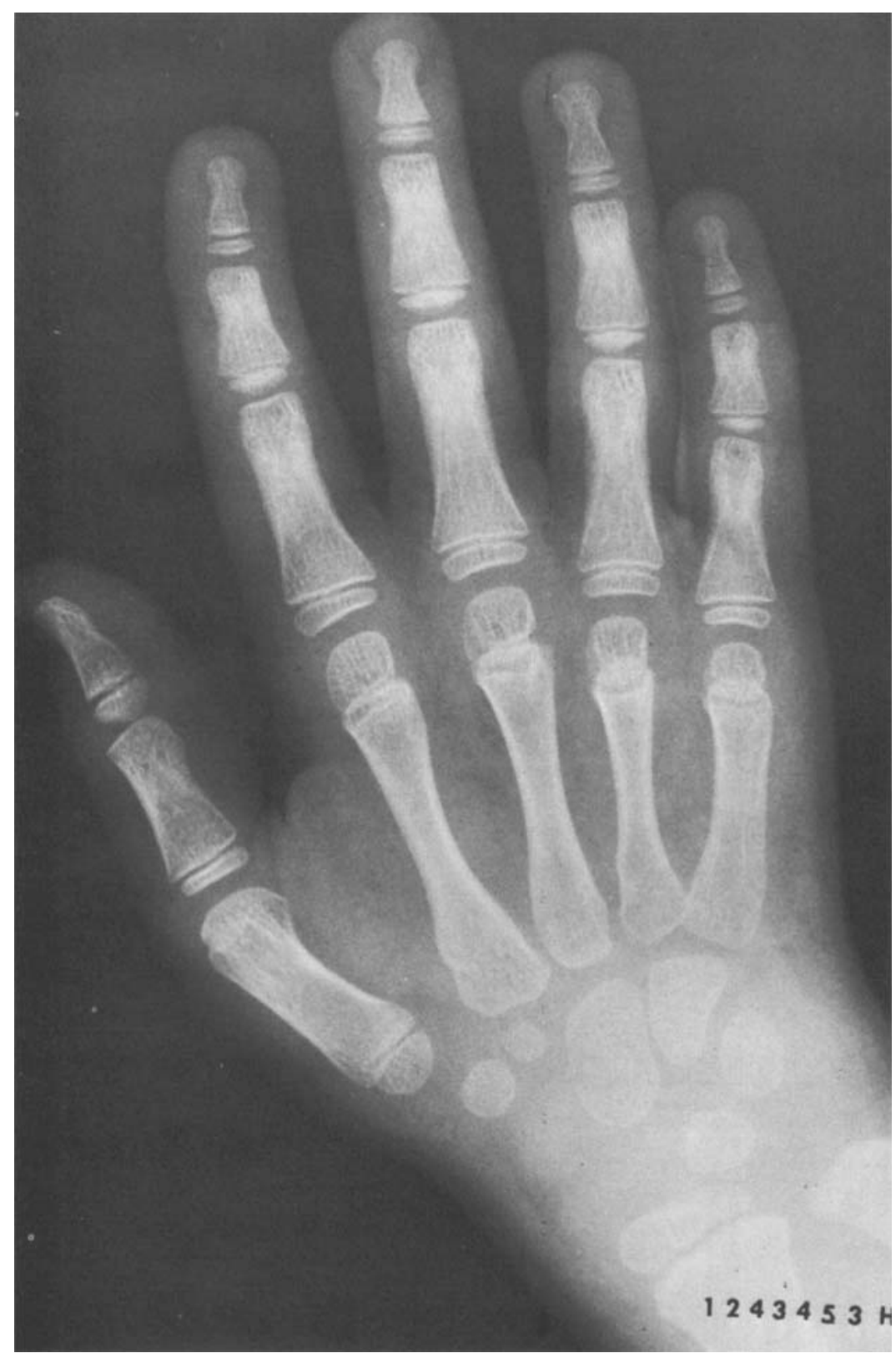

Fig. 3 Disproportion in phalangeal and carpal ossification in cerebral gigantism. Five and three-tenths year old male. The overall maturation is advanced, but there is also relative advancement of the phalanges as compared to the carpals. The phalangeal maturation is somewhere between eight and nine years, while the carpals are nearer to seven, although there is considerable intercarpal variation. Note also the marked delay in scaphoid ossification which is common in these children. 

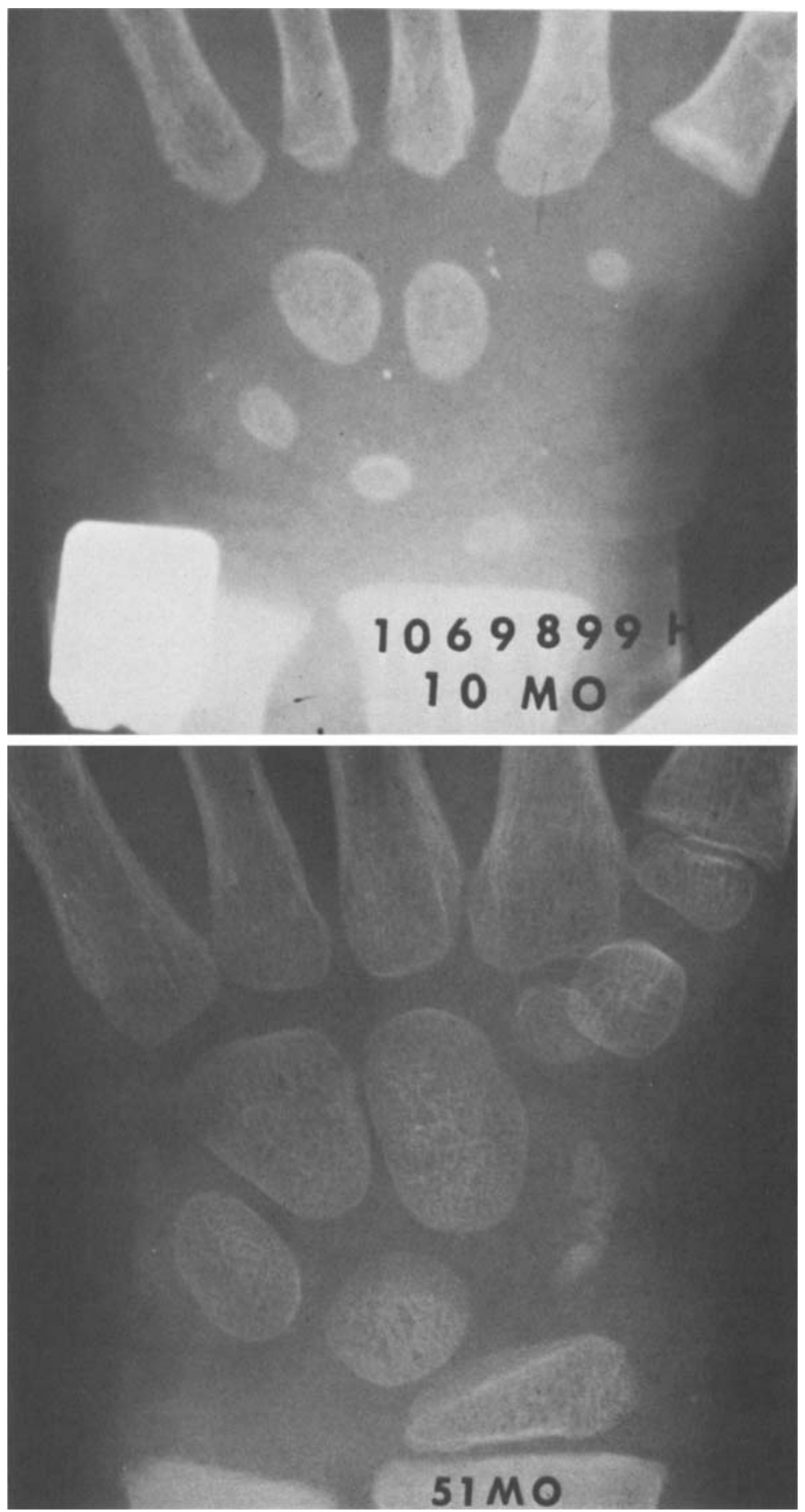

Fig. 4 Relative scaphoid delay in a cerebral giant. The carpals are advanced for age, both at ten months and $\mathbf{5 1}$ months, but the scaphoid is retarded in relation to the other carpals. The phalanges were ahead of the carpals at 51 months and behind them at ten months (table 3, K.B.). 


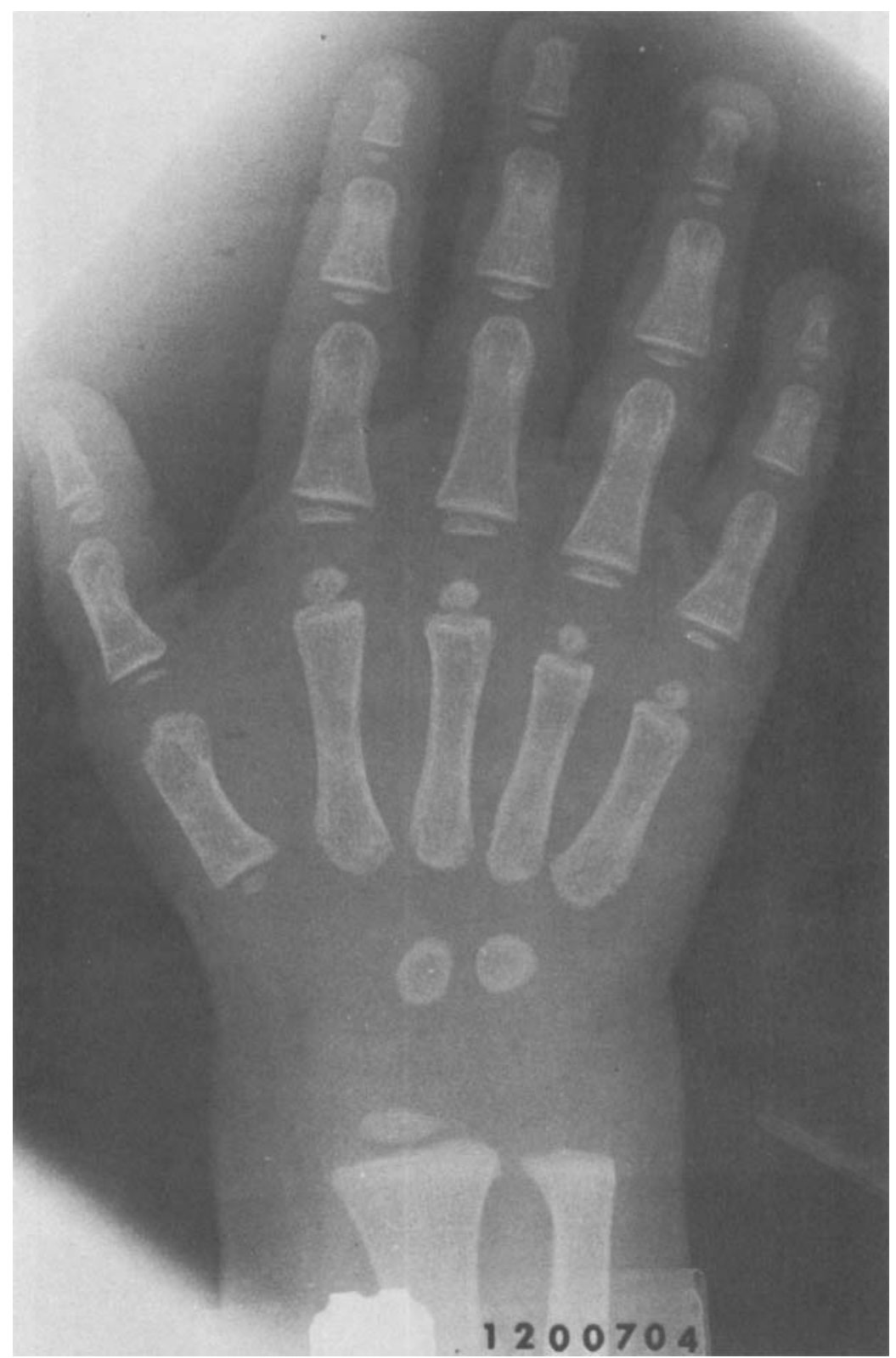

Fig. 5 Relative advancement of phalanges over carpals in the adrenogenital syndrome Fourteen month old with salt-losing form of adrenogenital syndrome. Child had female karyotype. The phalangeal epiphyses show marked advancement in maturation (about 30 months) The metacarpals are intermediate ( 22 months), while the carpals are least advanced, having a maturation between 12 and 15 months. 


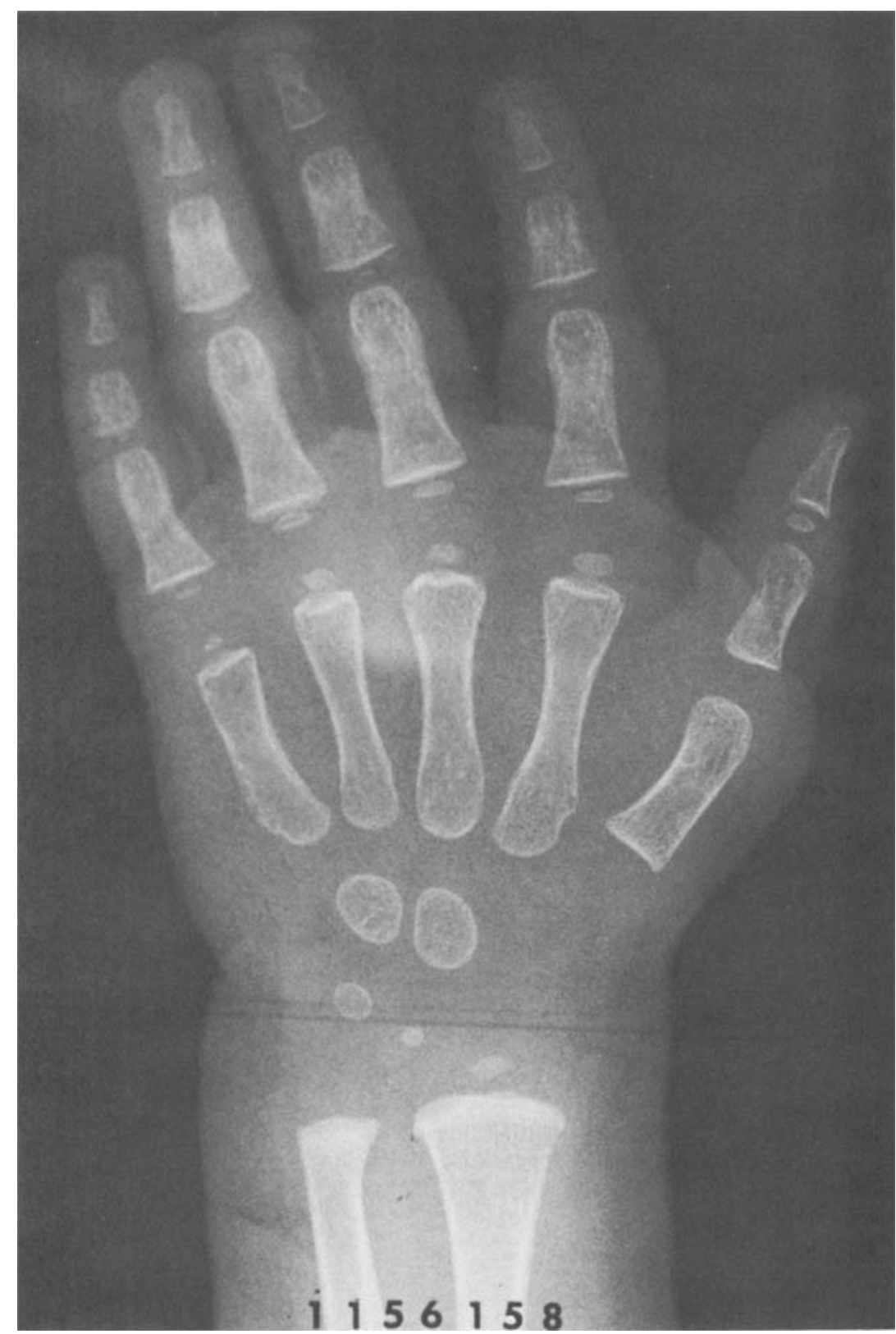

Fig. 6 Advanced carpal over phalangeal maturation in an 11.5 month fermale who developed premature thelarche at two years of age. Four carpals are present while the distal phalangeal epiphyses have not yet ossified. A less marked difference was evident at two years of age. The pattern of relative carpal advancement is more common in normally advanced children than in the malformation syndromes. 


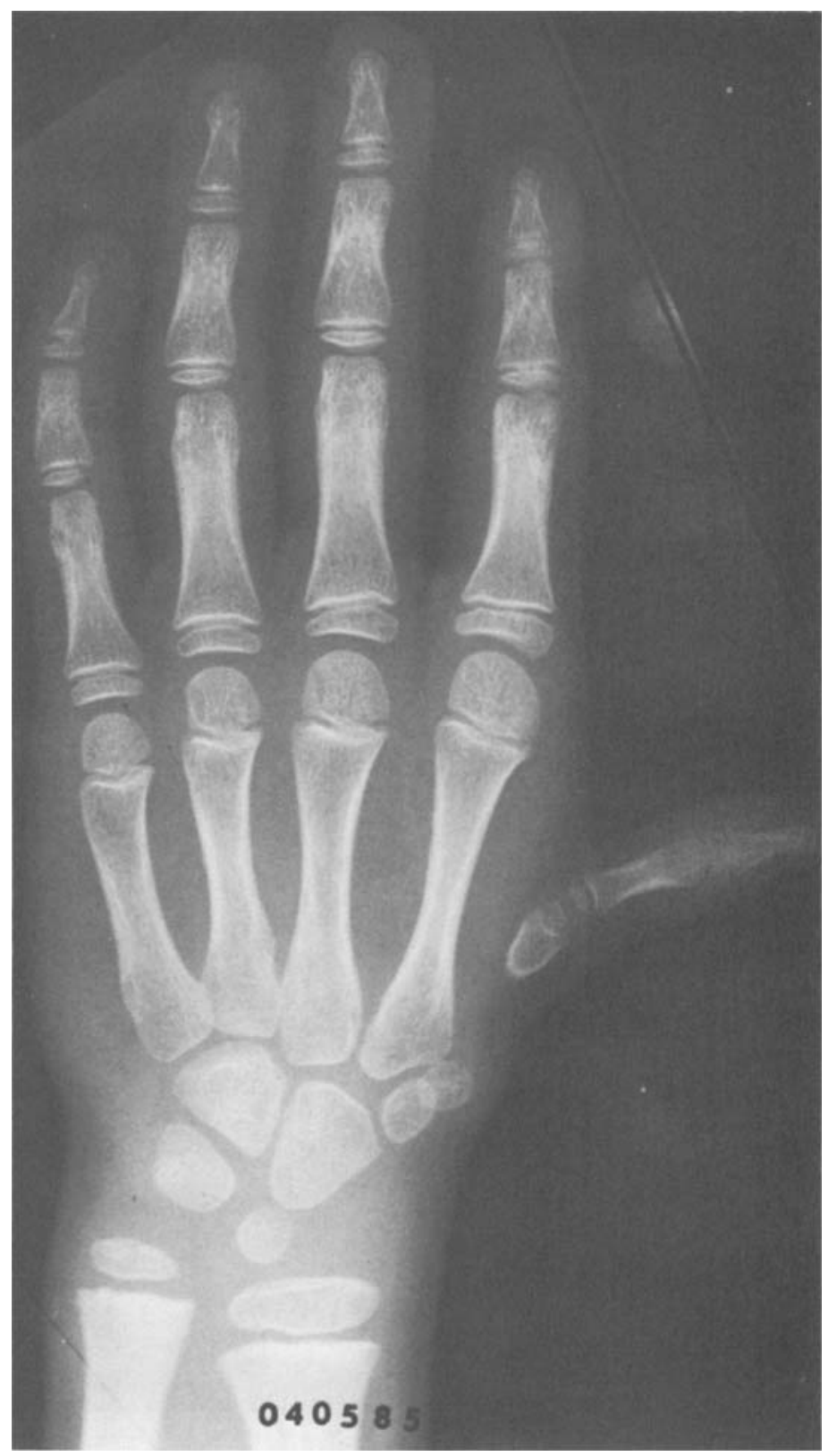

Fig. 7 Juberg-Hayward syndrome with absent scaphoid and hypoplastic thumb in a 7.4 year old boy. Absence or hypoplasia of the scaphoid is usually seen in syndromes that are associated with radial or thumb hypoplasia. 
and was most marked with the late carpals. In fact in one individual the carpals were more advanced at 0.8 years while the opposite was true at 4.3 years. Part of the delay in the carpals was the result of a relative delay in the scaphoid (fig. 4). The common male sequence of lunatescaphoid-trapezium-trapezoid did not occur in most cases (table 4). In all five individuals whose ossification was such that at least one, but not all, of the late carpal centers were ossified, the trapezium or trapezoid was ossified, while the scaphoid was not yet present. In others, even when present, the scaphoid was relatively hypoplastic (fig. 4). The scaphoid,
TABLE 4

Delayed appearance of the scaphoid in cerebral giants

\begin{tabular}{|c|c|c|c|c|c|}
\hline \multirow{2}{*}{ Center } & \multicolumn{5}{|c|}{$\begin{array}{l}\text { Presence or absence } \\
\text { in patients }\end{array}$} \\
\hline & 1 & 2 & 3 & 4 & 5 \\
\hline Epiphysis metacarpal 1 & + & + & + & + & 0 \\
\hline Epiphysis proximal phalanx 1 & + & + & + & + & 0 \\
\hline Epiphysis distal phalanx 2 & + & + & + & + & 0 \\
\hline Epiphysis distal phalanx 5 & + & + & + & + & 0 \\
\hline Epiphysis middle phalanx 5 & + & + & + & + & 0 \\
\hline Lunate & + & + & + & + & + \\
\hline Scaphoid & 0 & 0 & 0 & 0 & 0 \\
\hline Trapezium & + & + & + & + & + \\
\hline Trapezoid & 0 & 0 & + & + & 0 \\
\hline Distal epiphysis ulna & 0 & 0 & 0 & 0 & 0 \\
\hline
\end{tabular}

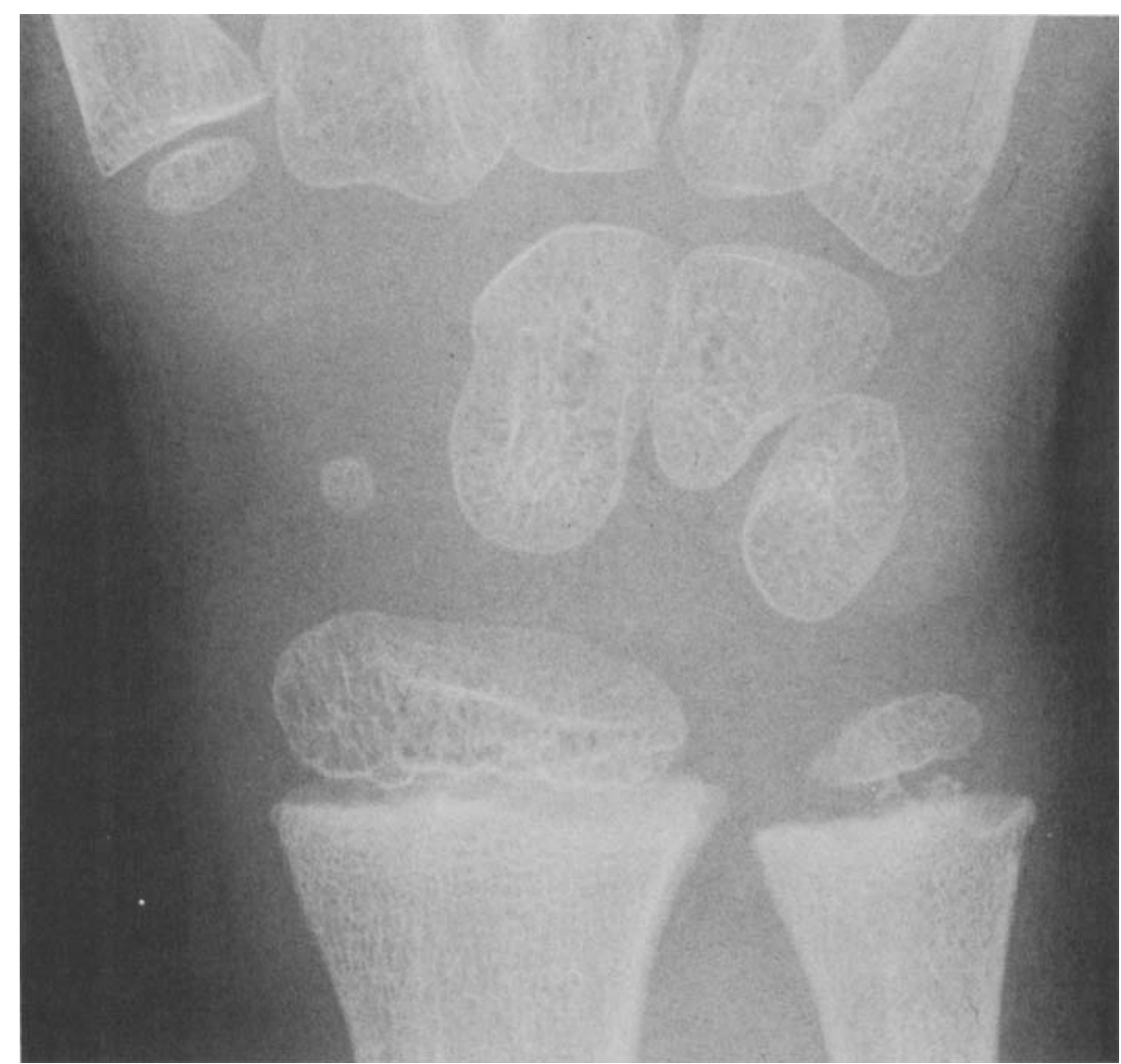

Fig. 8 Delayed lunate and other carpals in homocystinuria. Seven year old boy. There is lack of ossification of the trapezoid and lunate and marked retardation of ossification of the scaphoid and trapezium. When the child was 8.5 years, ossification of these four bones had progressed, but they were still markedly delayed. Considerable side to side asymmetry was also evident. Bony spicules, which are characteristic of the condition, are seen in the distal ulna. 
however, is a variable bone and its delay in comparison to the trapezium or trapezoid occurred in 8.3 of children in the ninety-fifth percentile in the ten state Nutrition Survey.

The pattern of relative carpal delay in children with advanced maturation was uncommon in the ten state Nutrition Survey (table 1). Comparison of this population with the cerebral giants is, how- ever, only partially valid since the former were evaluated in terms of onset while the cerebral giants were evaluated both on the basis of onsets and maturity indicators. The pattern of relatively advanced epiphyses as compared to the carpals is not unique to cerebral gigantism, but may occasionally occur in other conditions with advanced maturation, such as in the adrenogenital syndrome (fig. 5).

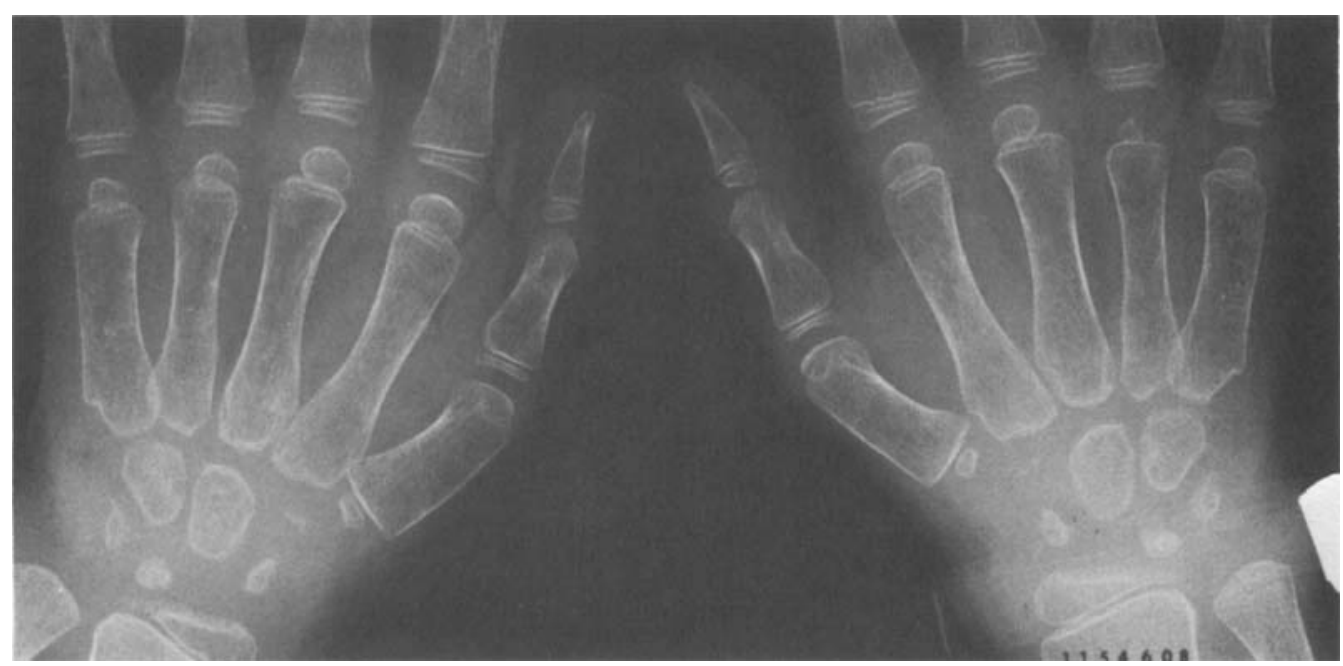

Fig. 9 Maturation delay due to local factors. Five and two-tenths year old with rheumatoid arthritis. Note delay in ossification of epiphyses of the fourth right metacarpal and irregularity of the carpal centers. Many of the carpals are delayed in ossification.
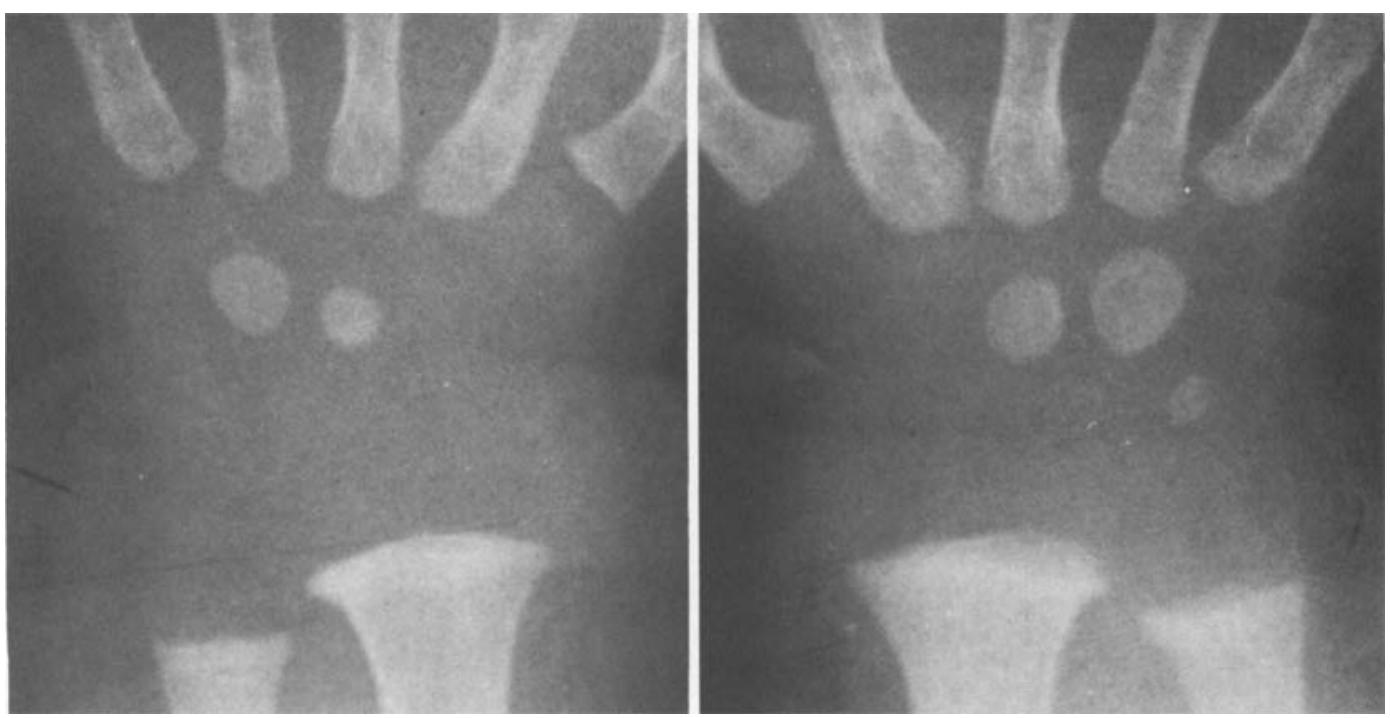

Fig. 10 Asymmetry in a three month old male with hemihypertrophy. The capitate and hamate are better developed on the right than on the left and the triquetrum is seen only on the left. 
Less commonly in abnormalities of maturation, the carpals are advanced ahead of the phalanges. This pattern was seen in the ninety-fifth percentile group of the ten state Nutrition Survey and occasionally in other conditions (fig. 6).

\section{DELAY OF SPECIFIC CENTERS}

Various conditions with isolated carpal retardations are also known. The scaphoid bone is normally very variable in maturation. A greater scaphoid delay than in cerebral gigantism is usually present in syndromes associated with radial or thumb hypoplasia. This includes conditions such as Fanconi's anemia and the Juberg-Hayward syndrome (Juberg-Hayward, '69) as shown in figure 7. The scaphoid is often not present even though the other ossification centers are well defined. The Juberg-Hayward syndrome is a rare familial condition which includes hypoplasia of the thumb, cleft lip and palate, microcephaly, congenital heart disease, as well as other anomalies (Poznanski, Garn and Holt, '71).

Delay or absence of the capitate, as well as other distal row carpals, has been described in some epiphyseal dysplasias (Silverman, '61). In one of his cases the capitate remained absent at age 16 when all the epiphyses were fused. Other carpals were markedly hypoplastic.

A relatively large capitate and a delay in the lunate has been described in homocystinuria (Morreels et al., '68). In pa-
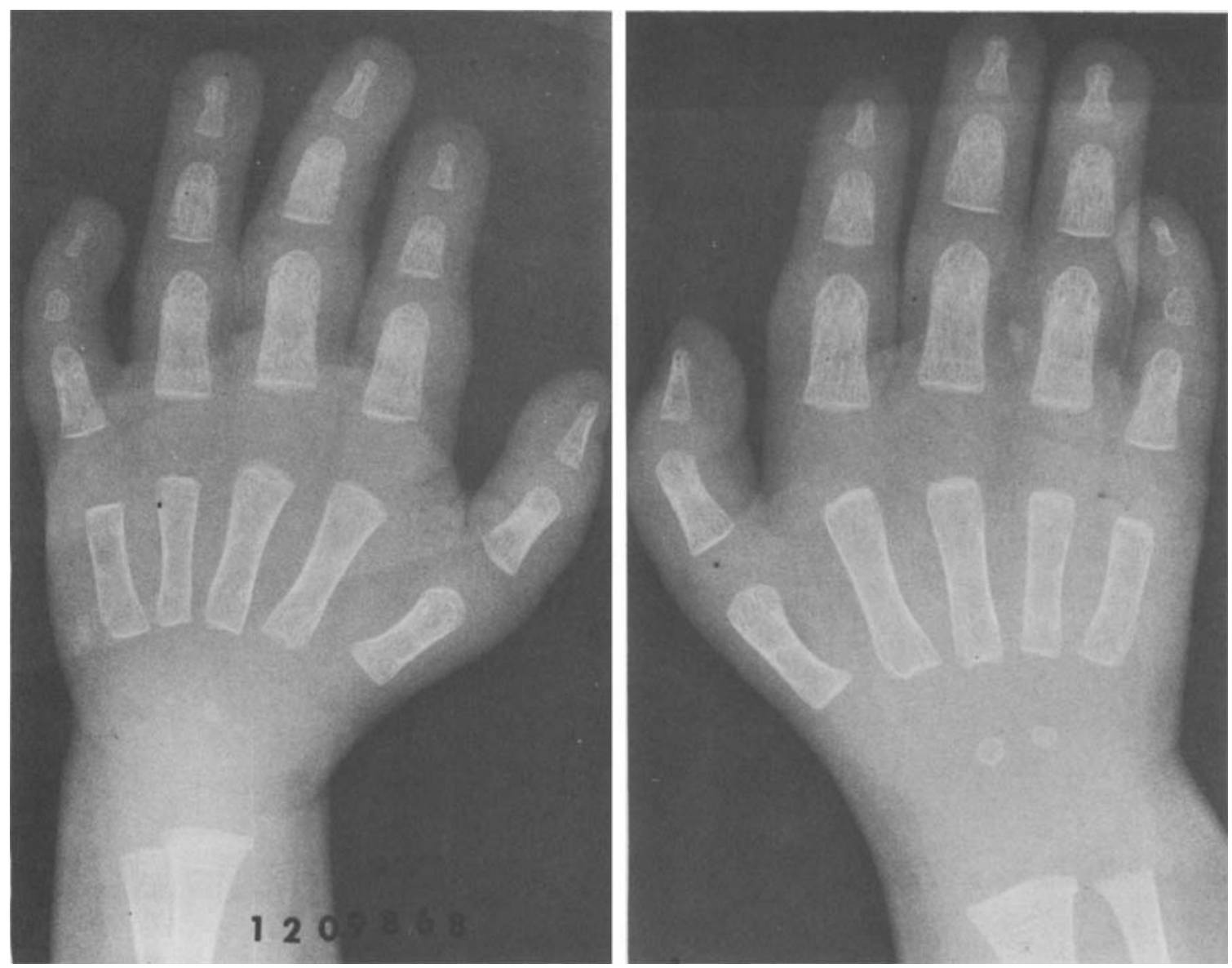

Fig. 11 Asymmetric maturation in 11 month male with Silver's syndrome. The capitate and hamate are better developed on the right. The entire right side of the body is larger than the left, and all of the ossification centers were more mature on the right. Note also clinodactyly and brachymesophalangia $\mathrm{V}$ which is characteristic of this condition. 
tients seen in our institution (Holt and Allen, '67), a delayed lunate was seen in one patient, as well as relative hypoplasia of several other carpals (fig. 8).

Carpal delays are also seen in many conditions with gross irregularity of carpals or epiphyses where meaningful evaluation of maturation is not possible. Delay of all carpals, but particularly the scaphoid, has been described in Morquio's disease (Langer and Carey, '66). In spondyloepiphyseal dysplasia (Spranger and Langer, '70) carpal ossification is retarded, particularly in the proximal row.

Isolated retardation or advanced maturation of phalangeal epiphyseal centers is not common in the congenital malformation syndromes except when associated with gross abnormality, such as in Apert's syndrome (Poznanski, Garn and Holt, "71). Local trauma, exostoses, or inflammatory diseases, such as rheumatoid arthritis, may affect a single center (fig. 9).

\section{ASYMMETRY}

Variation in maturation between the left and right hands may occur in a normal population, but the differences are minimal (Greulich and Pyle, "59). The carpals, which are the most variable bones in the hand, have the greatest degree of asymmetry (Baer and Durkatz, '57). In a group of malnourished children studied by Dreizen et al. (57), some asymmetry was detected in most cases with the right hand being more mature than the left in $52 \%$, the right equal to the left in $26 \%$, and the right less mature

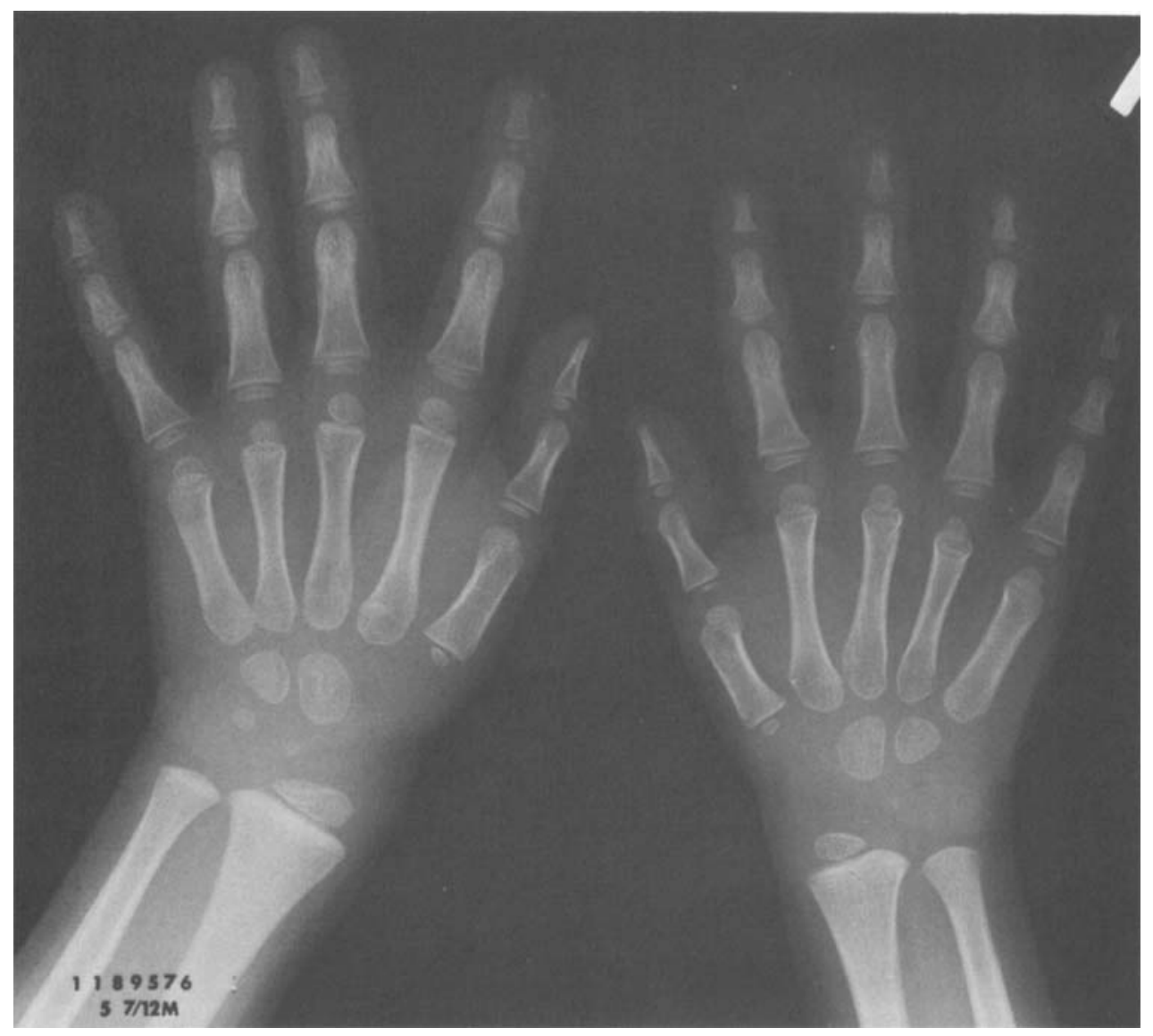

Fig. 12 Delayed maturation on the right due to spastic hemiplegia of unknown cause. Five year seven month old boy. The triquetrum which has appeared on the right is absent on the left. All of the epiphyses are less mature on the right. 
than the left in $22 \%$. However, the differences between the hands were small. There was more than three months difference between the hands in only $13 \%$ of cases and more than six months in only $1.5 \%$. The asymmetry in maturation within the bones of each hand was greater than between the two hands in more than $98 \%$ of his cases.

A number of local factors, particularly those which cause increased vascularity in extremities, such as hemangioma, arteriovenous malformation, rheumatoid arthritis, pyarthroses, can all cause an increase in maturation of one side as compared to the other.
Hemihypertrophy is frequently associated with differences in maturation (Anderson, '67). This pattern may be seen in idiopathic hemihypertrophy (fig. 10) and in hemihypertrophy associated with Silver's syndrome (fig, 11). Silver's syndrome is a form of primordial dwarfism which is characterized by clinodactyly of the fifth finger and asymmetry. The asymmetry of size and maturation is seen not only in the hand, but was evident in all other epiphyses and even in the spine.

A hypoplastic extremity, as may be seen in diastematomyelia (Poznanski, '70), or paralysis (fig. 12), is usually retarded
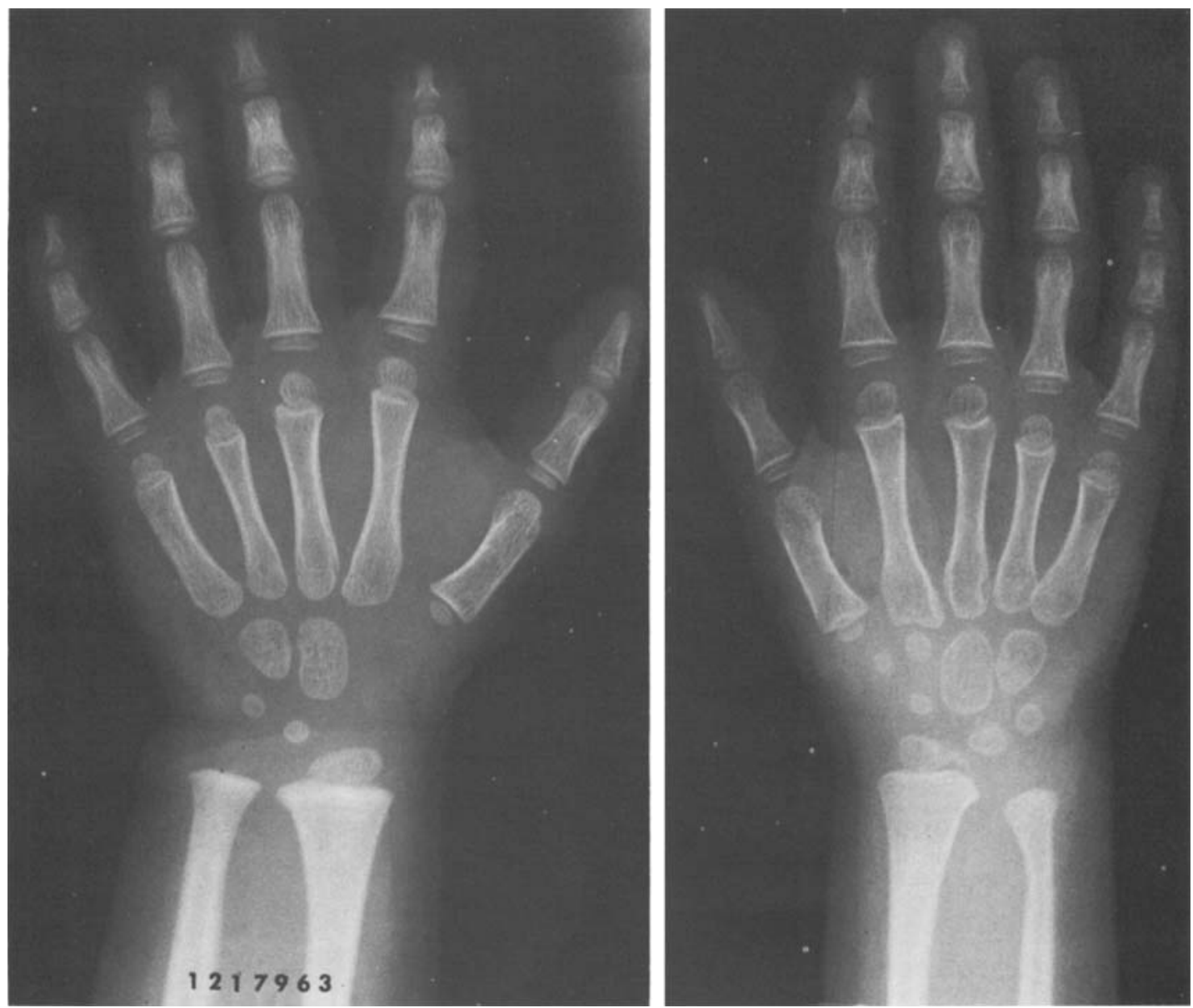

Fig. 13 Advanced maturation on hypoplastic side in a child with rheumatoid arthritis. This is contrary to the usual findings. This 28 month old female has slightly advanced carpal centers on the left but markedly advanced ones on the right. There is less asymmetry in the phalanges. Note the marked hypoplasia of the radial and ulnar shafts on the right. The increased maturation is most likely on the basis of hyperemia, while the hypoplasia is on the basis of disuse. 
in maturation when compared to the opposite side. However, this is not universal. Figure 13 illustrates a case where the opposite was true.

The use of only the left hand in evaluating maturation is valid for normal populations since the variations from side to side are small (Greulich and Pyle, '59). However, in the congenital malformation syndromes we have been usually obtaining both hands since in association with marked sequence variation there may be a higher degree of asymmetry.

\section{CONCLUSION}

Abnormal patterns of ossification in the congenital malformation syndromes may make the concept of skeletal age less meaningful. However, when the pattern is grossly different from normal it may be helpful in diagnosis.

\section{ACKNOWLEDGMENT}

The ten state Nutrition Survey was supported in part by contract HSM 110 . 69-22 with the Nutrition Section, Center for Disease Control, Atlanta, Georgia.

\section{LITERATURE CITED}

Anderson, M. 1967 Growth, overgrowth, and maturity: Observations based upon examination of serial roentgenograms of children with hemihypertrophy. Am. J. Phys. Anthrop., 27: 246 (Abstract 46).

Baer, M. J., and J. Durkatz 1957 Bilateral asymmetry in skeletal maturation of the hand and wrist: A roentgenographic analysis. Am. J. Phys. Anthrop., 15: 181-196.

Dreizen. S., R. M. Snodgrasse, H. Webb-Peploe, G. S. Parker and T. D. Spies 1957 Bilateral symmetry of skeletal maturation in the human hand and wrist. Am. J. Dis. Child., 93: 122172.

Dreizen, S., C. N. Spirakis and R. E. Stone 1964 Chronic under-nutrition and postnatal ossification. Am. J. Dis. Child,, 108: 44-52.

Garn, S. M., and C. G. Rohmann 1960a Variability in the order of ossification of the bony centers of the hand and wrist. Am. J. Phys. Anthrop., 18: 219-230.

- $1960 \mathrm{~b}$ The number of hand-wrist centers. Am. J. Phys. Anthrop., 18: 293-299.
Garn, S. M., C. G. Rohmann and T. Blumenthal 1966 Ossification sequence polymorphism and sexual dimorphism in skeletal development. Am. J. Phys. Anthrop., 24: 101-115.

Garn, S. M., C. G. Rohmann and A. A. Davis 1963 Genetics of hand-wrist ossification. Am. J. Phys. Anthrop., 21:33-40.

Garn, S. M.. C. G. Rohmann and F. N. Silverman 1967 Radiographic standards for postnatal ossification and tooth calcification. Medical Radiog. and Photog., 43: 45-67.

Greulich, W. W. and S. I. Pyle 1959 Radiographic Atlas of Skeletal Development of the Hand and Wrist. Stanford University Press, Stanford, California.

Holt, J. F., and R. J. Allen 1967 Radiologic signs in the primary aminoacidurias. Ann. Radiol., 10: 317-321.

Juberg, R. C., and J. R. Hayward 1969 A new familial syndrome of oral, cranial, and digital anomalies. J. Pediat., 74: 755-762.

Langer, L. O.. Jr., and L. S. Carey 1966 The roentgenographic features of the KS mucopolysaccharidosis of Morquio (Morquio-Brailsford's disease). Am. J. Roentgenol., Rad. Therapy and Nuclear Med., 97: 1-20.

Lee, M. M. C., S, M. Garn, C. G. Rohmann and P. W. McPhaden 1968 The clustering phenomenon and group-sequence of hand-wrist ossification centers, as illustrated by Chinese Children from Hong Kong. Hum. Biol., 40: 345-362.

Morreels, C. L. Jr., B. D. Fletcher, R. G. Weilbaecher and J. P. Dorst 1968 The roentgenographic features of homocystinuria. Radiology, 90: 1150-1158.

Ozonoff, M. B., H. L. Steinbach and P. Mamunes 1964 The trisomy 18 syndrome. Am. J. Roentgenol., Rad. Therapy and Nuclear Med., 91: $618-628$.

Poznanski, A. K. 1970 Foot manifestations of the congenital malformation syndromes. Seminars in Roentgen., 5: 354-366.

Poznanski, A. K., S. M. Garn and J. F. Holt 1971 The thumb in the congenital malformation syndromes. Radiology, 100: 115-129.

Poznanski, A. K., and J. M. Stephenson 1967 Radiographic findings in hypothalamic acceleration of growth associated with cerebral atrophy and mental retardation (cerebral gigantism). Radiology, 88: 446-456.

Silverman, F. N. 1961 Dysplasies epiphysaires: entite proteiforme. Ann. Radiol., 4: 833-867.

Spranger, J. W., and L. O. Langer, Jr. 1970 Spondyloepiphyseal dysplasia congenita. Radiology, 94: 313-322

Stuart, H. C., S. I. Pyle, J. Cornoni and R. B. Reed 1962 Onsets, completions and spans of ossification in the 29 bone-growth centers of the hand and wrist. Pediatrics, 29: 237-249. 